\title{
Research on Development Status, Problems and Prospects of Low - carbon Transportation Planning
}

\author{
Baozhong Wang ${ }^{1, a}$ \\ ${ }^{1}$ ZhengZhou Urban Planning Design \&Survey Research Institute, ZhengZhou, Henan, China, \\ 450052
}

Keywords: Development Status, Problems, Prospects, Low-carbon Transportation, Planning

\begin{abstract}
With the global climate change and low-carbon economy increasingly development, we are concerned about the transport and energy consumption and carbon dioxide emissions, the development of low-carbon transport has become a priority choice in the transportation industry emission reduction. As an energy power, China ranks first in the world in terms of carbon emissions. From the existing work, low-carbon transport has become an important direction for Chinese sustainable development. On the other hand, in the daily traffic planning, we should fully consolidate the transport planning stage result otherwise it will affect Chinese sustainable development.
\end{abstract}

\section{Introduction}

Low-carbon transport originated in the 1990s, 1993, "sustainable future transport: European example" and "transport, environment and sustainable development" through the United States and Western Europe and other developed countries, the impact of transport on the environment, the environment The value of the recommendations of the traffic policy and other aspects of the study, put forward the "sustainable development of transport" concept. In 1996, the World Bank published the Sustainable Development of Transport - Policy Reform Priority Project, which presented the concept of "sustainable transport", believing that sustainability was the basis for the development of transport policies. In 2000, the Organization for Economic Co-operation and Development (OECD) proposed the goal of building ".

Low-carbon transport refers to the full attention to carbon emissions in all aspects of transportation planning, operation, production, construction and management. By rationally guiding transportation needs, optimizing transportation equipment, transport structure and energy use structure, Operation and energy efficiency, and from the policy-oriented, technological innovation, social ethics, cultural cultivation and so on, together and maximize the total reduction of carbon emissions, and ultimately to achieve the whole cycle of transport, the whole industry chain low-carbon development concept, System and practice. Low-carbon transport is both to meet the normal needs of economic and social development, but also reduce the unit transport carbon intensity of the new industrial form.

Low-carbon transport planning is the basis for the development of low-carbon transport, the current low-carbon transport planning research focused on strategic planning, policy and regulatory and technical aspects. China has also introduced a series of transportation energy-saving emission reduction planning and related supporting rules and regulations, and promote low-carbon transport system. However, in the process of low-carbon transportation development, there is a series of problems such as lack of theoretical support and imperfect policy system. This paper will systematically analyze the policies, regulations and research status of Chinese low-carbon transportation planning, analyze the main problems existing in low-carbon transportation planning, speculate on the future research prospects of low-carbon transportation planning, and promote the development of low-carbon transportation industry in China.

\section{The Research Status Quo of Low Carbon Transport Planning}

Chinese low-carbon transport planning research in the time and effort and many, but the effect is 
not ideal, because there is no clear understanding of the current status of low-carbon transport planning, many problems are blind, to take Planning measures and programs, only on the surface of the effort, in essence, did not have too much positive significance for transportation planning. To this end, we should first sum up the status quo of low-carbon transport planning research, as the future development trend of the corresponding data and information for the implementation of measures and provisions of the formulation and lay a solid foundation.

Lack of Perfect Planning Theory and Method Support. At present, low-carbon transport planning, although the objective of the rigid requirements, but in the implementation of the relevant work, because there is no definite theory and methods, low-carbon areas of various regions show uneven characteristics. Combined with the previous work experience and the current work standards, the lack of a sound planning theory and method support, is a more important issue. The problem is concentrated in the following three aspects: First, low-carbon transport planning theory, methods, models and other basic research is rare. On the basis of the lack of various theoretical frameworks, access to a large number of data and information, do not know how to use, the development of measures to solve the chaos in the implementation process, may also cause some conflict, Transportation planning, it is very unreasonable. Second, many of the enterprises in the reality of low-carbon work, and did not be included in the overall planning, only in the country to crack down on the strike stage, or the introduction of preferential policies at the national stage, through a number of measures to obtain economic measures of the support, in fact, there is no too much positive significance for low-carbon traffic. Third, the place has been prepared planning or business and it cannot be through practical action to ensure the results of the work of the stage. From the beginning to the present, low-carbon transport planning, always maintained in place, not much change, resulting in planning work, encountered a lot of difficulties and obstacles.

Lack of Top Design and Overall Planning of National Low-Carbon Transport Development. The face of social carbon emissions increasing, low-carbon transport is imminent. However, due to the objective and subjective lack of national low-carbon transport development of the top design and overall planning, so in many work, did not achieve too much positive results, resulting in work efficiency and quality of work greatly reduced. The main problems in the following aspects, first, a single department of low-carbon work is relatively concentrated, objectively caused the neglect of the overall situation. The Chinese various modes of transport, roads, waterways, railways, aviation, will cause greater carbon emissions, if only in a single sector to carry out low-carbon work, then it will affect the overall low-carbon transport planning. Second, a variety of modes of transport low-carbon development, coordinated development goals and key tasks are not clear, the development path is not clear. From the subjective point of view, the more important issue at this stage is that low-carbon traffic is everyone can realize things, but how to plan, every year to get what kind of goals, the specific development of the line, are not established, resulting in a lot Work did not achieve a breakthrough effect. Therefore, the current stage of carbon emissions is still serious, the regional natural environment and the air environment have not been fully improved.

Lack of Supporting Policy System Design to Adapt to Low-Carbon Technology and Management Innovation. In the rapid economic development today, the natural environment and social environment, has been the businessman as the second status, the first position is the economic income (in the low-carbon transport planning process, due to lack of adaptation to low-carbon technology and management innovation supporting policies System design, leading to the specific work of the foothold cannot be determined, each region can only be based on the overall goal, the design of some tentative measures to each stage of the work results as a standard, if successful continue to implement, if the failure to stop implementing) This work is not only time-consuming, but also affects the overall development of the country. Lack of adaptation to low-carbon technology and management innovation supporting policy system design issues, mainly in the first, administrative supervision, laws and regulations, etc., are just starting work, not able to objectively form a working system, the work effect is not prominent. Second, the domestic energy-saving emission reduction and other aspects of the work more, but in the international voice is not sufficient and it cannot better lead the international cooperation, the environment is not for domestic 
low-carbon work to help.

\section{The Development Trend of Low-Carbon Transport Planning}

China as a developing country, low-carbon transport planning has become a very important work, and should be in the next few years to achieve success, otherwise it will encounter more problems. However, due to excessive carbon emissions, some simple measures can not complete the overall progress. In the future, we should work in both the details and the environment to consolidate our country's transportation planning, implement the low-carbon implementation, rather than just as a slogan.

The Green Low-Carbon Integrated Transport System Construction. Low-carbon transport planning development trends, should be moving in the direction of diversification, should promote Chinese comprehensive low-carbon. At the same time, in the specific work, should implement the stage of security work to prevent carbon emissions due to some problems once again raised, resulting in more serious losses. Green low-carbon integrated transport system construction is the focus of future work. At present, the investment in transportation is relatively large, and technical measures will be the main content of green and low carbon in the future. I believe that in the construction of the system, the future can try from the following aspects, to strengthen the low-carbon transport technology innovation, low-carbon policy system design, low-carbon management and other aspects of attention, while paying more attention to various modes of transport comparative advantage of the full play, especially to increase water transport, railways and other low-carbon transport policy support. Give priority to the development of public transport, through the optimization and upgrading of transport structure, to build a green low-carbon modern integrated transport system construction, from the source to reduce the impact of energy resources and ecological environment, with minimal resource and environmental costs to meet the needs of the largest transport services, for the realization of green and low carbon economy vision to provide strong support. It can be seen that the construction of green low-carbon integrated transport system has great positive significance for Chinese economic development and traffic development, and can continue to reduce carbon emissions in the future and promote the improvement of social environment and natural environment.

Focus on Strengthening the Theoretical Design and Top-Level Design of Low-Carbon Transport Strategic Planning. In the process of low-carbon transportation planning, the theoretical basis and top-level design of the planning should be further pursued to promote the concrete work towards the same goal and make full use of the low-carbon work that has been obtained. The current economic development is very rapid, low carbon will become an important measure of transport, strengthen the theoretical basis and the top design, to promote our early entry into the low carbon era. And constantly deepen the understanding of the development of low-carbon transport law and grasp, and timely adjustment of strategic planning to adapt to changing internal and external environment. While constantly optimizing the supply of transport services at the same time, pay more attention to the reasonable demand for transportation and management. In order to improve the maneuverability of planning, we should pay attention to the construction and perfection of planning theory system, the innovation of planning method, the application of quantitative model and software, the standardized management and democratic participation of planning, and so on. Transport planning research and practice to be particularly concerned about.

Pay More Attention to the Organic Combination of Government Public Policy Innovation and the Use of the Market Mechanisms. For low-carbon transport planning, a single effort is bound to fail to do more work. In the future, we should pay more attention to the organic combination of government public policy innovation and market mechanism. First, the need for research on market demand, low-carbon is a relatively large range of vocabulary, in order to be able to better solve the problems caused by carbon emissions, the need for a response to the market have a full understanding, and then develop the appropriate countermeasures. Second, the government's public policy cannot always focus on state-owned enterprises and local enterprises, to deal with some private enterprises and developing enterprises to invest more preferential policies to promote 
its low-carbon work to make greater contributions. Third, the use of economic, legal, administrative and other means, on the one hand to limit the impact of low-carbon transport factors, on the other hand to facilitate the work of low-carbon, should focus on the use of the prevailing guidelines, the carbon emissions of large work, effective conversion for low-carbon work to promote the construction of transportation planning,

\section{Conclusion}

From the point of view of existing work, low-carbon transport planning is no longer an empty talk, but a lot of work are implemented to the social development, the overall economic and social benefits is worthy of recognition. In the future work, we need to further improve the low-carbon transport system, policy, planning, conditions, etc., to promote Chinese low-carbon work level.

\section{References}

[1] Jia Xinzhang, Li Jingyuan. Hunan Transportation Technology, Vol. 6 (2014) No 53, p.25-26

[2] Wang Yunhui, Wang Qunyong. Traffic Standardization, Vol. 12 (2015) No 27, p.74-76

[3] Qian Xiyuan, Jing Jianfen. Traffic Standardization, Vol. 30 (2014) No 19, p.144-145

[4] Wang Kuailiang. China Circulation Economy, Vol. 29 (2008) No 27, p.21-23

[5] Zhang Gongxu, Sun Jing. Ecological Economy, Vol. 8 (2013) No 27, p.57-60 